\title{
CATEGORISING GEOTECHNICAL PROPERTIES OF SURFERS PARADISE SOIL USING GEOGRAPHIC INFORMATION SYSTEM (GIS)
}

\author{
Haider Al-Ani ${ }^{1}$, Leila Eslami-Andargoli ${ }^{2}$, Erwin $\mathrm{Oh}^{1}$, and Gary Chai ${ }^{3}$ \\ ${ }^{1}$ School of Engineering, Griffith University, Australia \\ ${ }^{2}$ School of Environment, Griffith University, Australia \\ ${ }^{3}$ Centre for Infrastructure and Engineering Management, Griffith University, Australia
}

\begin{abstract}
Peat is a highly organic and compressible soil. Surfers Paradise (as a study area) has problematic peat layer which has different thickness at different locations between R.L. -10 to $-19.6 \mathrm{~m}$ below the ground surface. Buildings in Surfers Paradise are using piled foundations to avoid the high compressibility and low shear strength peat layer. In this paper, geotechnical borelogs are compiled from 51 soil investigation reports in the study area. These borelogs data are then imported into ArcGIS10 as digital layers and converted into assessable formats by Geographic Information System (GIS). This technique has been utilised to produce digital zonation maps for the study area. The application of interpolation techniques allows the production of zonation maps and bring together years of geotechnical data. Standard Penetration Test (SPT) N values have been selected to determine the soil stiffness in the study area. These SPT-N values are then categorised to produce different zonation maps. The occurrence of peat layers can be located using these zonation maps. These GIS-based zonation maps will provide a better overview of subsurface geology, bed rock elevations, and geotechnical properties of the various soil types found in the study area.
\end{abstract}

Keywords: Peat, Geographic Information System, Standard Penetration Test, Spatial Analyst.

\section{INTRODUCTION}

GIS has the capability to manage, store, and referencing geotechnical data to its geographic locations. It has been used to integrate existing data such as soil investigations aided by geographic coordinates with specific project data to identify potential geotechnical challenges. For instance, a case study has been presented by [1] where a geotechnical investigation data has been managed by using GIS for design purposes in transportation projects. The outcome of this study was an early identification of the geotechnical problems which require an additional budget and time consuming design's substantial changes. It is generally accepted that the organic matter presence in soils causes a detriment of their geotechnical and engineering qualities [2]. Peats and organic clays cause typical geotechnical problems as a result of their characteristics such as compressibility, lightness, creep ability, weatherability, and low strength and stiffness [3].

\section{GIS APPLICATION IN GEOTECHNICAL DATA}

GIS has been used in many geotechnical applications ubiquitously over the world. For example, in Brazil, GIS used for geotechnical and environmental risk management of Brazilian oil pipeline in 2010 [4].
In addition, in Greece, GIS has been used to produce a thematic map for the geotechnical, geological, seismological, and geomorphological data of Athens [5]. In Turkey, reference [6] has used GIS to produce zonation maps and to estimate if a further precaution is required for a safer area. Cross sections which include SPT-N blow count with depth have been performed to determine the soil strength. Further, GIS-based geotechnical information systems have been established in the USA, Singapore, Brazil, and Japan in 2003, 2005, 2003, and 2010 respectively. The purpose of this is a web-based easy access to the geotechnical data of any area of interest to have an idea about geotechnical conditions of this area. In addition, four case studies of small scale geotechnical projects have been studied by [7] to verify the benefits of using GIS in geotechnical engineering in The United Kingdom. The outcome of this study indicated that GIS output improved the analytical and technical range of these projects in comparison with traditional techniques and the high quality produced maps are comprehensible and popular with engineers.

This paper shows the identification of peat layer occurrence in Surfers Paradise as a case study in Australia. The occurrence of peat has been identified by producing the interpolated SPT-N value zonation maps by using the Spatial Analyst extension and interpolation techniques. Peat occurrence's depth and thickness have been also determined in the study area. 


\section{METHODOLOGY}

Two approaches have been utilised to produce GISbased SPT- $N$ value zonation maps. The first approach was by collecting the geotechnical data from the geotechnical investigation reports. These data were available in many different locations and forms. Next, data has been tabulated by using Excel to make it familiar with the GIS environment. The spatial locations of boreholes have been designated by using Google Earth based on boreholes actual locations on each project's site plan. By calculating the distances between separate boreholes and the distance between the borehole itself and the adjacent boundaries on the site plan, boreholes' coordinates can be acquired from Google Earth. Randomly chosen boreholes have been chosen to validate coordinates before transferring these coordinates into GIS environment.

Figure 1 shows the procedure of obtaining the boreholes coordinates from a project site plan. Figure 2 illustrates the transformation of geotechnical data from Excel spread sheets into ArcMap. The red dots on the GIS map represent the borehole's spatial locations. Each borehole has its own spatial data as well as geotechnical data which have been uploaded from Excel. It can be observed from Fig. 2 that the geotechnical data has been horizontally tabulated in Excel sheet in a way to be compatible with the GIS setting.

The second approach has been achieved by examining eight interpolation techniques in the Spatial and Geostatistical Analyst in ArcMap10. The purpose of this approach is to interpolate the SPT- $N$ value and producing the zonation maps.

The eight interpolation techniques examined were: (1) Geostatistical Analyst Tools, IDW method (2) Geostatistical Analyst Tools, Diffusion method (3) Geostatistical Analyst Tools, Global Polynomial method (4) Geostatistical Analyst Tools, Kernel method (5) Spatial Analyst Tools, Ordinary Kriging (6) Spatial Analyst Tools, Universal Kriging (7) Spatial Analyst Tools, Spline (8) Spatial Analyst Tools, IDW method.

The interpolation technique of Spatial Analyst Inverse Distance Weighting method (IDW) was the most suitable technique which gives a better representation for the SPT- $N$ data in Surfers Paradise with specific parameters. This is consistent with what [8] has found.

The spatial analyst extension employs the Inverse Distance Weighting (IDW) interpolation method to create these maps. The interpolation, in turn, is a procedure being used to predict the values of cells at certain locations that lack sampled points [9].

\section{STUDY AREA}

Surfers Paradise has a unique prominent location which increases the tourism and commercial activities in Gold Coast in the state of Queensland, Australia. It has been an iconic tourist destination since 1950s and it is the most famous location in Australia. Surfers Paradise has an area about 4 by $1.3 \mathrm{~km}^{2}$ and the Nerang River divided it into two main parts Nerang River parts, and Beach side part. The study area includes the area which is located between the Nerang River and the Coral Sea (Fig.3).

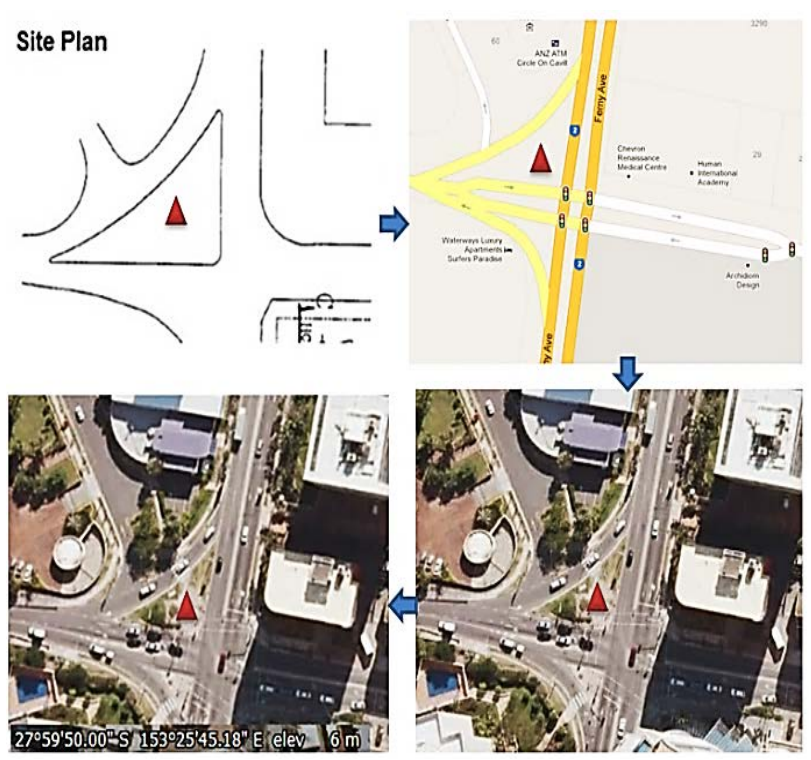

Fig. 1 Designation of boreholes geographic coordinates

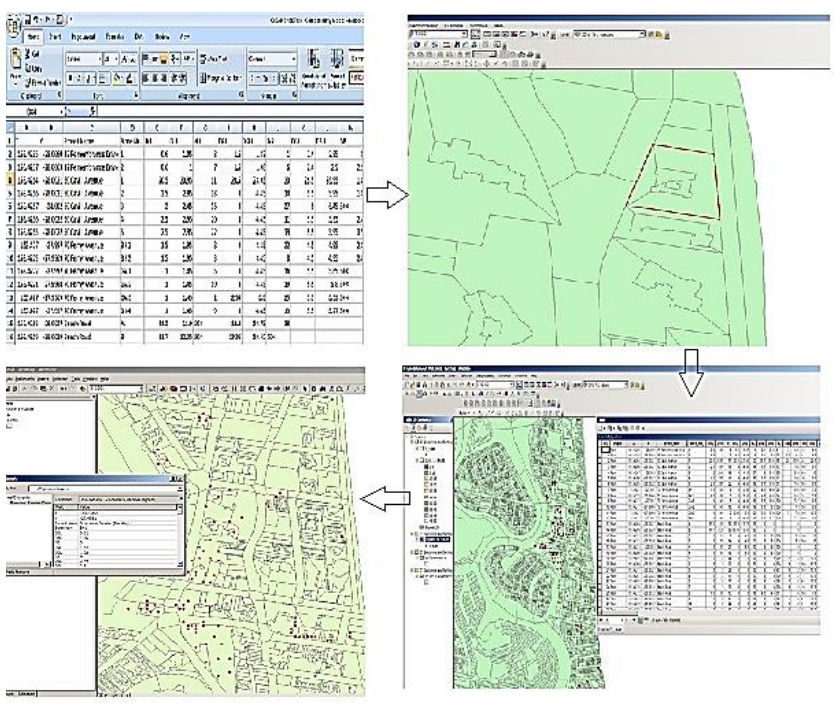

Fig. 2 Geotechnical data transformation into GIS environment

The soil profile of the study area contains different soil types which are as follow:

- Loose to medium dense sand starts from the ground surface to R.L. $2.3 \mathrm{~m}$.

- Medium dense to dense sand is underlain from (R.L. $2.3 \mathrm{~m}$ ) to (R.L. -3.2 m).

- $\quad$ Very dense sand is encountered from (R.L. -3.2 m) to (R.L. - $20 \mathrm{~m}$ ). 
- Within the very dense sand layer, a varying thickness peat layer is occurred at depth between (R.L. -10 to R.L. $-19.6 \mathrm{~m}$ ) at different locations with thickness ranges from $(0.1-7$ $\mathrm{m})$.

- An interbedded firm to very stiff clay layers are found up to (R.L. -26.6 m) where a layer of firm to hard clay is occurred below it until the depth (R.L. $-29 \mathrm{~m}$ ).

- The last layer of this soil profile varies within the study area where in some locations there is an interbedded layer of medium dense sand, gravelly sand, clayey sand, sandy clay, or hard silty clay can be observed.

This soil profile is consistent with the description given by [10] , [11] and [12].

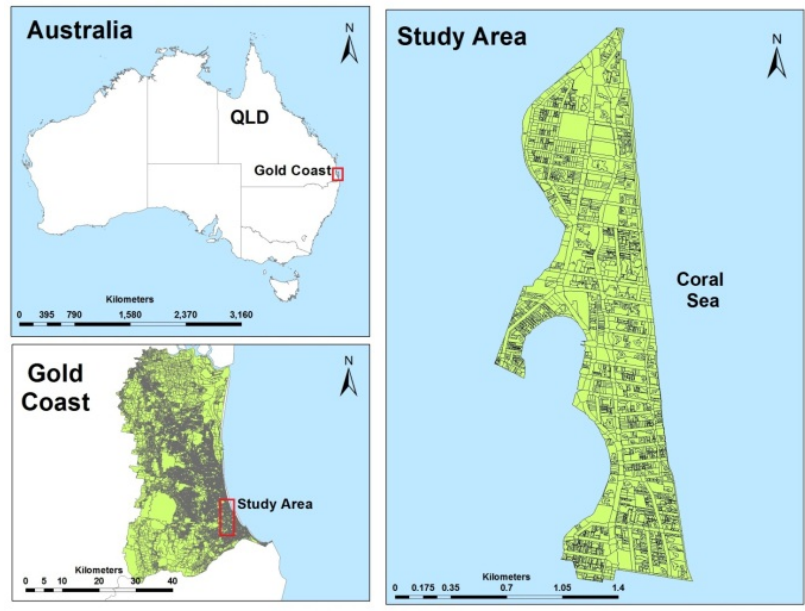

Fig. 3 the location of the study area

\section{RESULTS AND DISCUSSIONS}

Twenty six GIS-based interpolated maps have been performed for the study area at depths ranged between the ground surfaces until depth of R.L -40. These maps have been produced by using the Spatial Analyst IDW technique which has been selected among eight interpolation techniques to give a better representation of the data with specific parameters. These parameters are: output cell size: $2.719 \mathrm{E}-05$, power 2, search radius: fixed, and distance 0.25 .

In this paper, only four GIS-based SPT- $N$ value zonation maps have been provided to represent different depth classes. These four zonation maps represent different depth levels (near the surface until R.L. -26.6 $\mathrm{m})$. Also, it shows variety of soil classes in terms of SPT$N$ values.

Further, peat occurrence locations map is also presented for the study area. These locations are associated with its boreholes to show the peat depth and thickness in each location.
The first zonation map is nearly shallow in depth R.L. 2.3 to $0 \mathrm{~m}$. The Australian Height Datum (AHD) has been used for the depth considerations. Figure 4 shows the distribution of the soil stiffness values in the study area. It can be observed that the SPT- $N$ value in the northern parts of the study area was between 0-10 blows for very loose to loose sand. Whereas, in the southern parts was quite high $>30$ blows which represents dense sand. The sand classification has been adopted based on [13] in terms of number of blows of the SPT. There are some locations within the study area are not spatially interpolated and it seems to be blank due to the lack of geotechnical data in this depth at these locations. The second SPT- $N$ value zonation map has been performed for the depth between R.L. -13 to $-15 \mathrm{~m}$ (Fig. 5). It can be seen that the dominant soil stiffness value for this depth is between 31-49 blows which can be classified as dense sand. There are also some locations of very loose sand and loose sand of SPT-N value between 0-10 blow. Figure 6 shows the third zonation map for the SPT-N value at depth between R.L. -20 to $-21.6 \mathrm{~m}$. It can be noticed that the extent of this zonation map is smaller than the previous zonation maps. This is because the lack of data at this depth level which prevents the interpolation process to be completed in the unclassified (un-interpolated) areas.

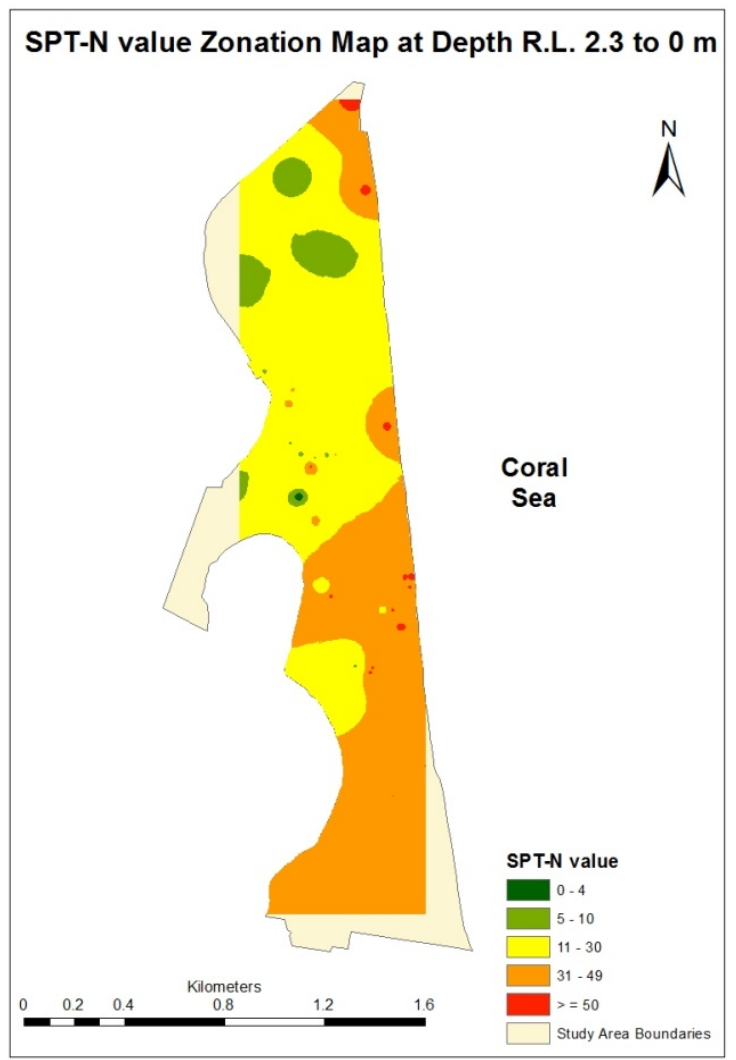

Fig. 4 SPT-N value zonation map at depth R.L. 2.3-0 m 


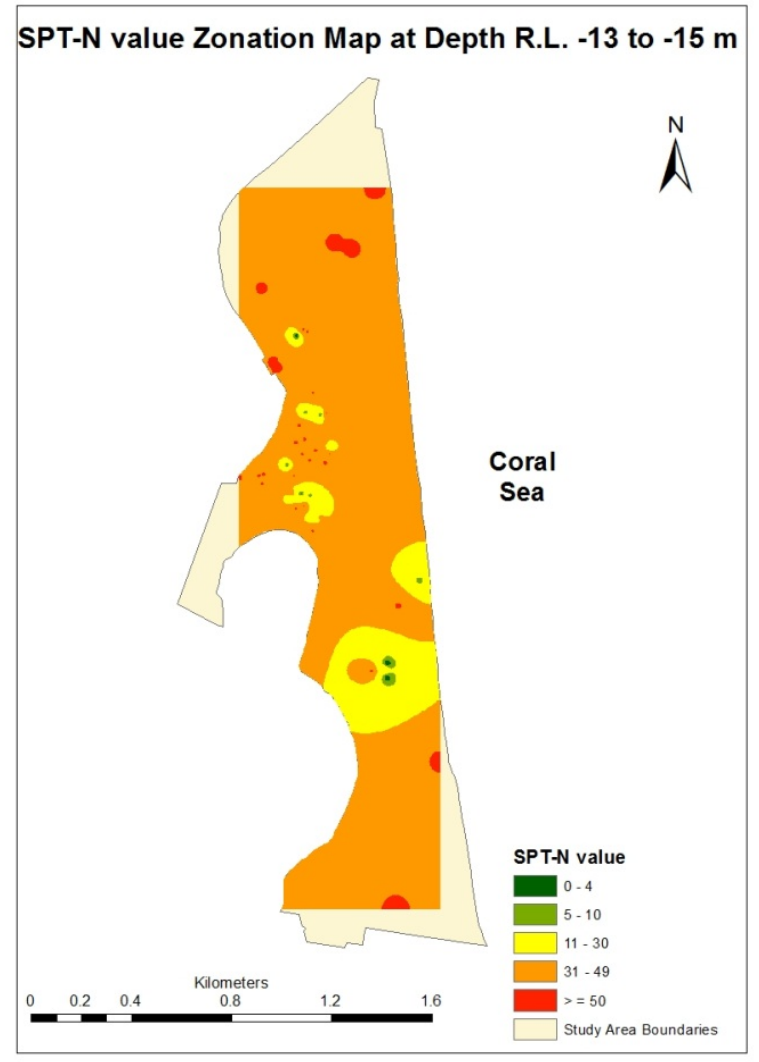

Fig. 5 SPT-N value zonation map at depth R.L. -13 to $15 \mathrm{~m}$

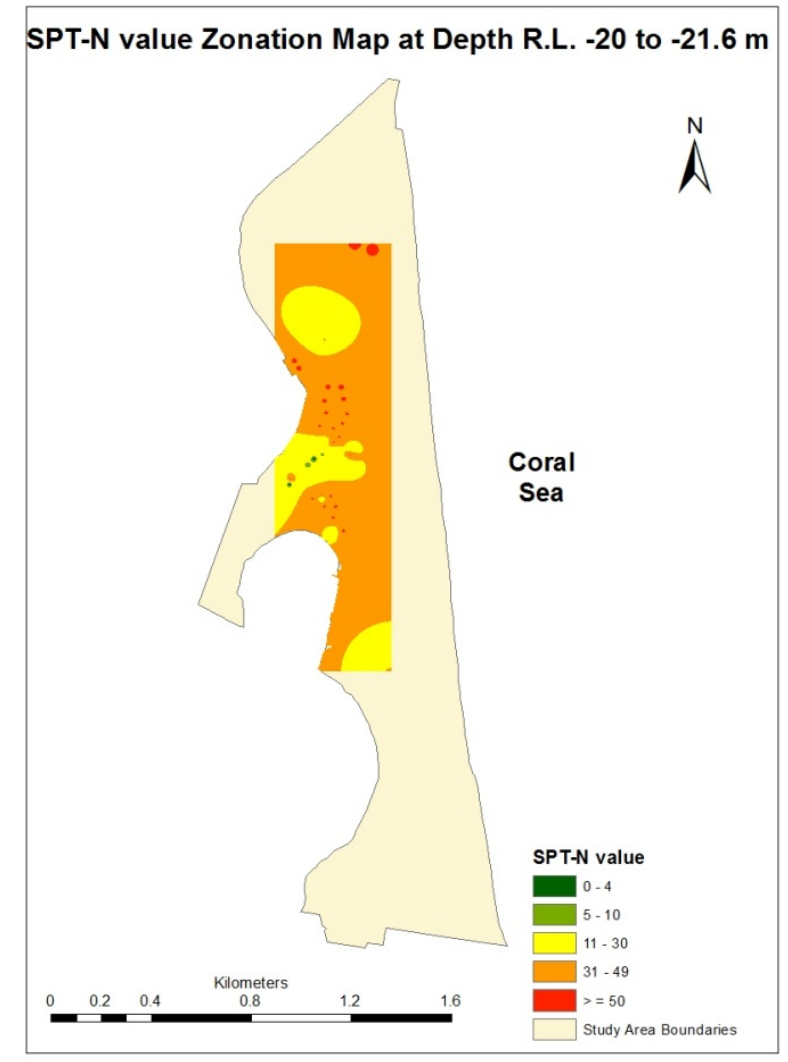

Fig. 6 SPT-N value zonation map at depth R.L. -20 to $21.6 \mathrm{~m}$
The last zonation map for the soil stiffness in this paper is located at depth between R.L. -25 to $-26.6 \mathrm{~m}$. Figure 7 shows the distribution of the SPT-N value within the study area and indicates that the dominant value for this depth is between 11-30 blows. This is because of interbedded layers of soft to firm clay and medium dense sand. Very loose sandy clay is also existed in the northern part of the study area.

Nonetheless, Peat locations have been identified within the study area in 16 locations (Fig. 8). These locations represent already existed buildings and other engineering structures in Surfers Paradise [10]. Each location in this figure has been given a number to denote peat's depth and thickness in this particular location (Table 1). Figure 9 shows the borehole distribution of these locations within the study area. These boreholes contain peat in its soil profile.

It can be seen from Table 1 that peat layer has a varying thickness which ranges between $0.0-7.0 \mathrm{~m}$ at depth mainly between R.L. -10 to $-19.6 \mathrm{~m}$ below the ground surface.

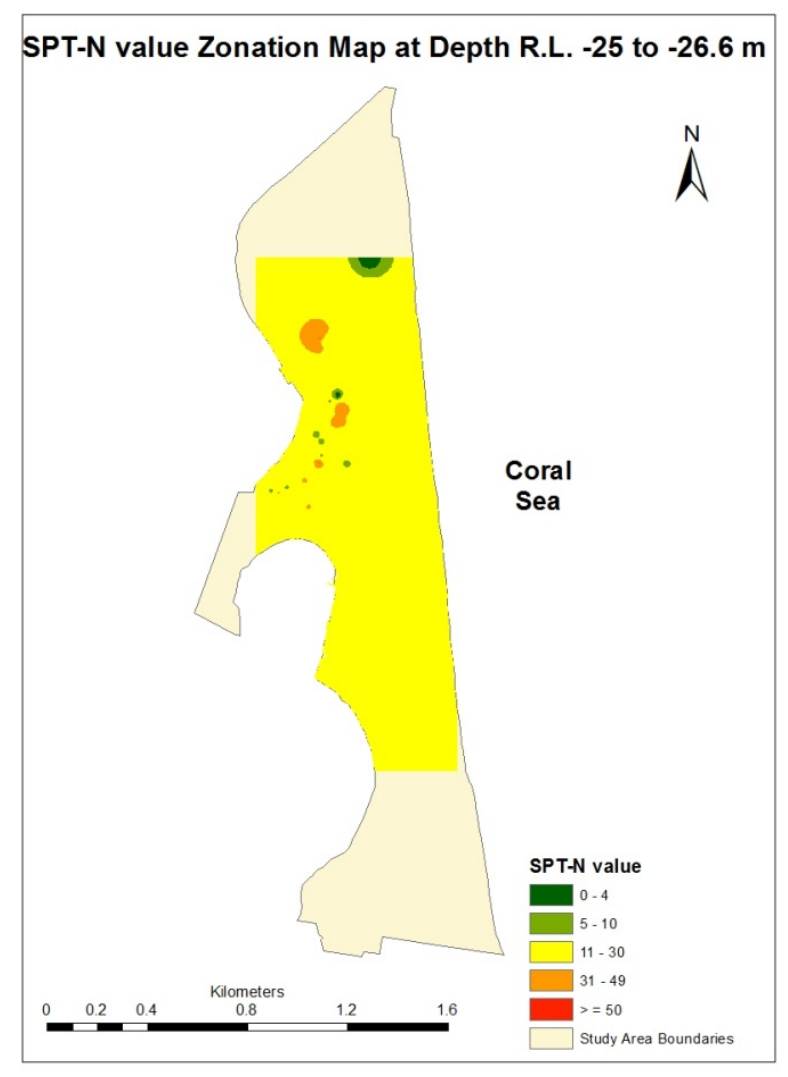

Fig. 7 SPT-N value zonation map at depth R.L. -25 to $26.6 \mathrm{~m}$

As mentioned, peat is geotechnically problematic soil and many engineers try to avoid the adventure of construction over peat. Therefore, attention is required for the already existed buildings and safety precaution is also necessary to be taken for the proposed new engineering structures in the peat locations. Approximately all the buildings in the study area are 
supported by pile foundations. Thus, this study will be useful for the potential engineering structures to take into account the depth and the thickness of peat for a suitable, economic, and safe design in Surfers Paradise.

Table 1 Peat depths and thickness in the study area

\begin{tabular}{ccc}
\hline Location & $\begin{array}{c}\text { Peat Depth } \\
(\mathrm{m})\end{array}$ & $\begin{array}{c}\text { Peat Thickness } \\
(\mathrm{m})\end{array}$ \\
\hline 1 & $27.2-32.2$ & 5.0 \\
2 & $1.2-6.7$ & 5.5 \\
3 & $14.9-17.5$ & 2.6 \\
4 & $12.6-14.4$ & 1.8 \\
5 & $16.0-23.0$ & 7.0 \\
6 & $17.75-21$ & 3.25 \\
7 & $17.1-18.3$ & 1.2 \\
8 & $18.0-22.5$ & 4.5 \\
9 & $17.0-20.0$ & 3.0 \\
10 & $15.4-19.4$ & 4.0 \\
11 & $17.7-21.7$ & 4.0 \\
12 & $11.6-12.4$ & 0.8 \\
13 & $11.3-12.5$ & 1.2 \\
14 & $21.4-23$ & 1.6 \\
15 & $17.0-22.0$ & 5.0 \\
16 & $0-1.5$ & 1.5 \\
\hline
\end{tabular}

Note: Depth is below the ground surface

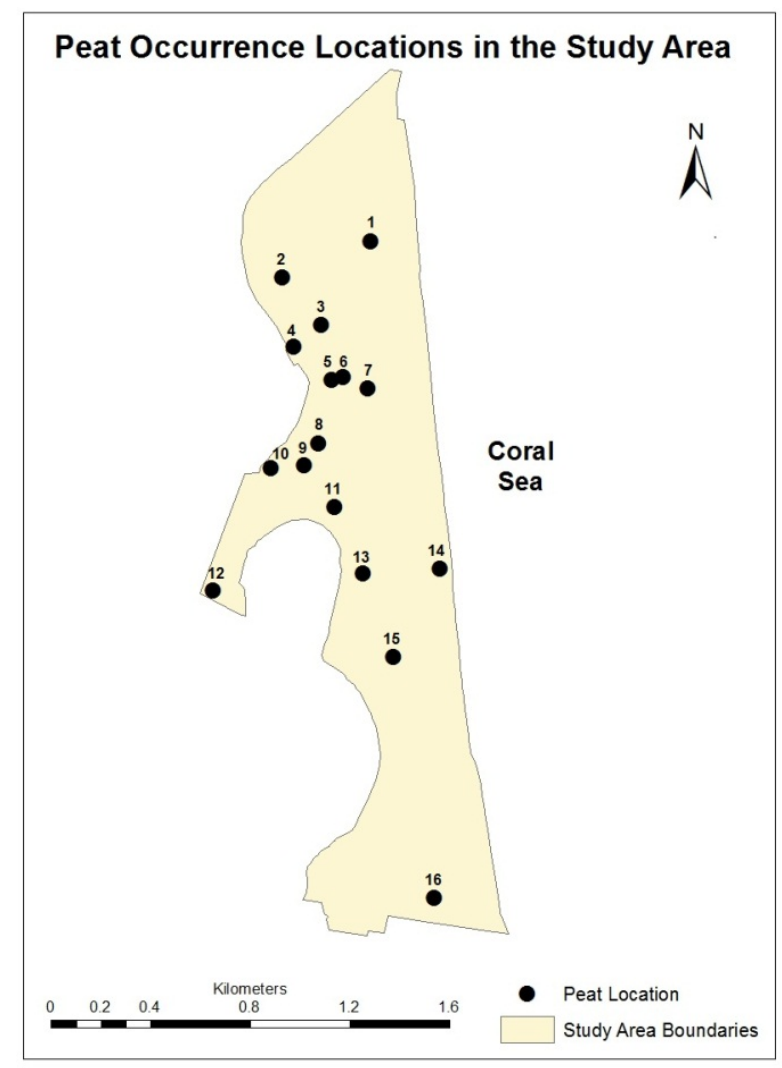

Fig. 8 Peat occurrence locations in the study area

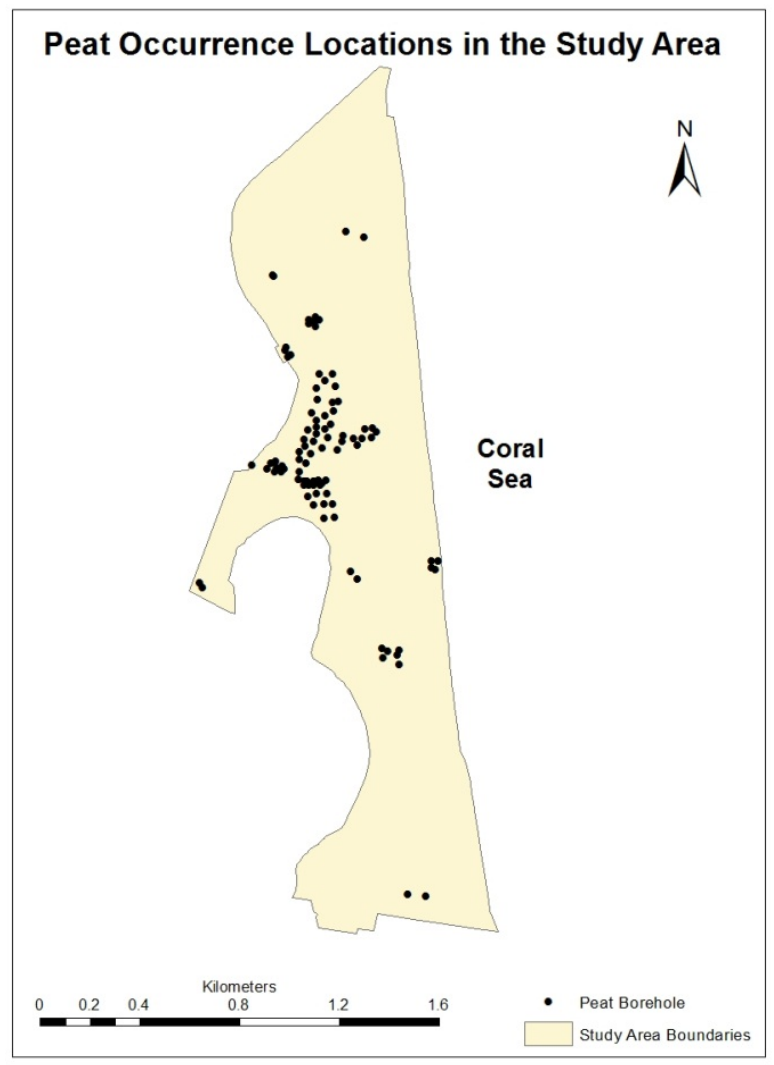

Fig. 9 Peat contained boreholes in the study area

\section{CONCLUSION}

To conclude, eight interpolation techniques have been used to characterise the subsoil conditions in Surfers Paradise. The Inverse Distance Weighting (IDW) technique within the Spatial Analyst in ArcMap10 showed a better representation for the Standard Penetration Test (SPT) N values with a certain parameters. Based on this, 26 interpolated SPT-N values zonation maps have been performed to characterise the soil in terms of soil stiffness by using the IDW technique.

Peat is highly organic and compressible and it has been considered as a geotechnically problematic layer. This layer has a varying thickness ranges between 0.1$7.0 \mathrm{~m}$ at depth between R.L. -10 to $-19.6 \mathrm{~m}$ below the ground surface in the study area. In addition, attention should be paid in terms of potential foundations challenges, to locations which have a high thickness of peat such as a location in the core of the study area which has a peat thickness of $7.0 \mathrm{~m}$. This study might be beneficial for public agency geotechnical engineers and decision makers at local and state levels.

This paper is a part from an ongoing research to characterise physical and engineering properties soil in Surfers Paradise in Southeast Queensland, Australia. 


\section{REFERENCES}

[1] Player RSV, "Geotechnical Engineering for Transportation Projects”, GeoTrans 2004, 2004, p.p. 886-893.

[2] Malkawi AIH, Alawneh, AS \& Abu-Safaqah, "Effects of organic matter on the physical and the physicochemical properties of an illitic soil", Journal of Applied Clay Science, Vol. 14, no. 5-6, 1999, pp. 257-278,

[3] Haan EJ and Kruse GAM, "Characterisation and engineering properties of Dutch peats”, Vol. 3, Ed. Tan TS , Phoon KK , Hight DW \& Leroueil S, Taylor \& Francis Group, London, , 2007, pp. 21012133.

[4] Augusto FO, Hirai JN, Oliveria AS \& Liotti ES, "GIS applied to geotechnical and environmental risk management in a Brazilian oil pipeline”, Bulletin of Engineering Geology and The Environment, Vol. 69, 2010, pp. 631-641.

[5] Antoniou AA, Papadimitriou AG \& Tsiambaos G, "A geographical information system managing geotechnical data for Athens (Greece) and its use for automated seismic microzonation”, Natural Hazards, Vol. 47, 2008, pp. 369-395.

[6] Orhan A and Tosun H, "Visualization of geotechnical data by means of geographic information system: a case study in Eskisehir city (NW Turkey)”, Environmental Earth Sciences, Vol. 61, 2010, pp. 455-465.

[7] Hellawell EE, Lamont-Black J, Kemp AC, and Hughes J, "GIS as a toll in Geotechnical Engineering”, Geotechnical Engineering, Vol. 149 (2), 2001, pp. 85-93.

[8] Al-Ani H, Oh E, Leila E, Chai G, "Subsurface Visualization of Peat and Soil by using GIS in
Surfers Paradise, Southeast Queensland, Australia”, Electronic Journal of Geotechnical Engineering, Vol. 18, June 2013, Bund.I, 171.

[9] Childs, C, "Interpolating Surfaces in ArcGIS Spatial Analyst”, ArcUser, Vol. July-September, 2004, pp. 32-35.

[10] Al-Ani H, Oh E, Chai G, "Engineering properties of peat in estuarine environment”, in in Proc. $1^{\text {st }}$ Int. Conf. on Foundation and Soft Ground Engineering Challenges in Mekong Delta, 2013, pp. 181-191.

[11]Oh, EYN, Huang M, Surarak, C, Adamec, R \& Balasurbamaniam, AS, "Finite Element Modelling for Piled Raft Foundation in Sand”, in Eleventh East Asia-Pacific Conference on Structural Engg. \& Const. (EASEC-11) "Building a Sustainable Environment”, Taipei, Taiwan, 2008, p. 8.

[12][12] Al-Ani H, Oh E, Chai G, "Characteristics of Embedded Peat in Coastal Environments", International Journal of Geomate, Vol.5, No.2, pp.609-618.

[13]Look, BG, "Handbook of Geotechnical Investigation and Design Tables”, London, Taylor \& Francis, 2007, ch.5. , p.55.

Int. J. of GEOMATE, Dec, 2013, Vol. 5, No. 2 (Sl. No. 10), pp. 690-695.

MS No. 3114a received on June 13, 2013 and reviewed under GEOMATE publication policies. Copyright (C) 2013, International Journal of GEOMATE. All rights reserved, including the making of copies unless permission is obtained from the copyright proprietors. Pertinent discussion including authors' closure, if any, will be published in the Dec. 2014 if the discussion is received by June, 2014.

Corresponding Author: Haider Al-Ani 